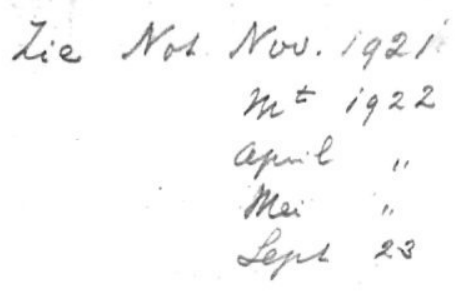

\title{
DE WONING VAN DIRK VAN HOGENDORP IN BRAZILIË (1817-1822)
}

(MET TWEE PLATEN).

Uit de gegevens, vermeld in de voorrede der «Mémoires du général Dirk van Hogendorp (1887)» en verwerkt in Sillem's levensschets van Dirk van Hogendorp (1890) was bekend, dat deze oudere broeder van Gijsbert Karel zijn laatste levensjaren gesleten had op een koffie- en sinaasappel-plantage (chacra, chacara) op de helling van den Corcovado, niet ver van een uitzicht over de baai van Rio de Janeiro. Van huis en plantage zelf, Novo-Sion genoemd naar een herinnering uit Dirk's jeugdjaren - het buitengoed Sion bij Delft —, was intusschen geen spoor te bekennen.

Een navraag, in 1919 gericht tot de Nederlandsche legatie, leidde tot niets. De toenmalige gezant schreef in Maart 1921, dat het resultaat van alle ter zake ingestelde nasporingen negatief was geweest.

In den zomer van 1922 evenwel nam de nieuwbenoemde gezant te Rio, Mr. Th. B. Pleyte, het onderzoek wederom ter hand, en binnen enkele maanden gelukte het hem de vraag, waar Van Hogendorp's laatste woning gestaan had, volledig te beantwoorden.

Vijf opeenvolgende vondsten brachten over Van Hogendorp eenig licht.

1. Uit de boeken der Engelsche kerk te Rio bleek, dat Van Hogendorp begraven was geworden op 18 October 1822 op het kerkhof Gamboa (Sillem, blz. 346, geeft als zijn sterfdag: 29 October); het grafnommer echter werd niet ontdekt, en vermoed werd, dat het graf geruimd was.

2. Uit plattegrond-teekeningen van Rio en omgeving uit het begin der XIX ${ }^{\text {de }}$ eeuw moest worden opgemaakt, dat Van Hogendorp's woning op de Z. O. helling van den Corcovado te zoeken was, waar op de heuvels langs het dal van Laranjeiras, verscheiden landhoeven (chacara's) verrezen waren. Enkelen daarvan 


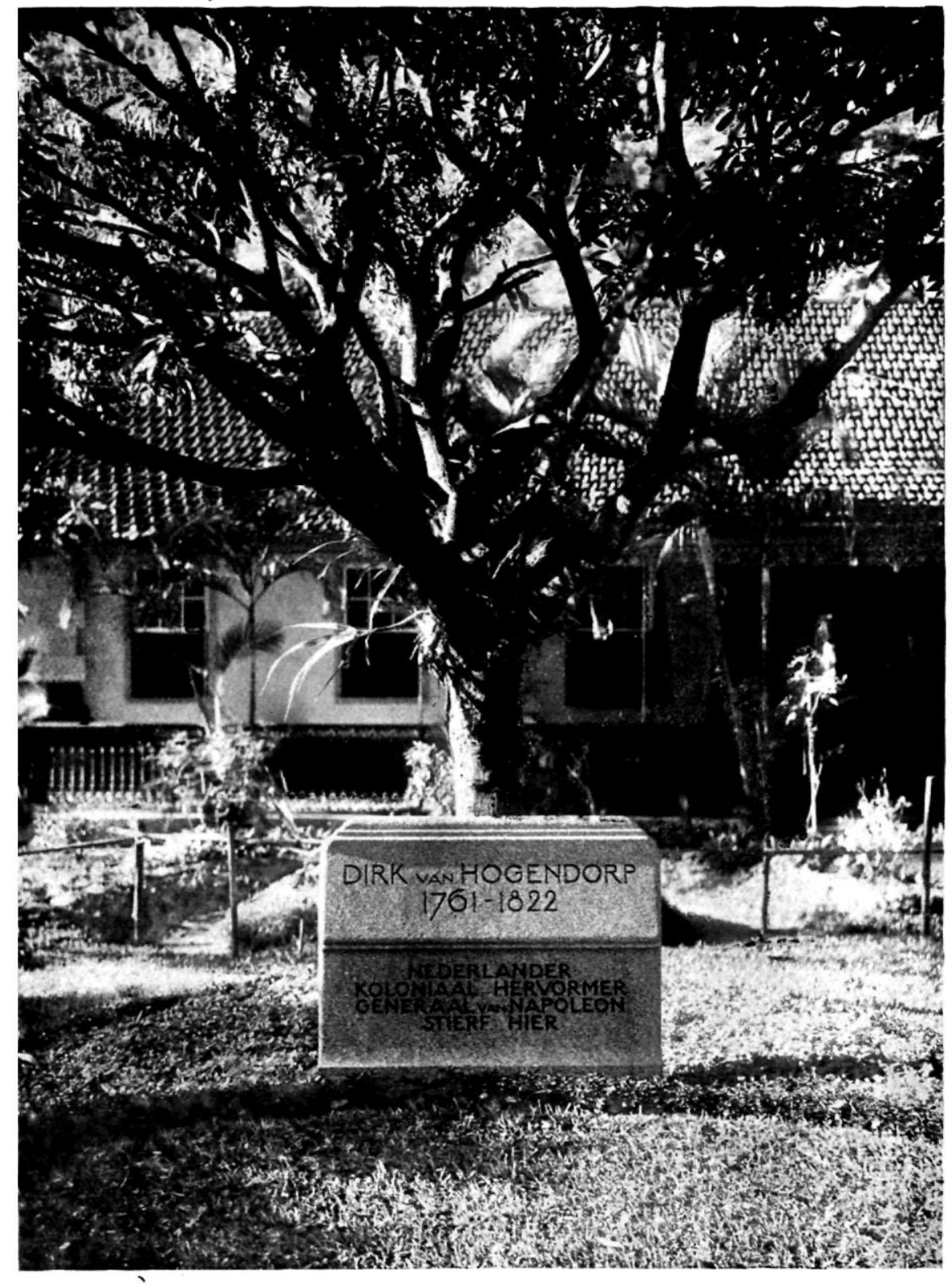

Gedenksteen voor Dirk van Hogendorp opgericht nabij Rio de Janeiro, op het terrein zijner aldaar in 1817 gevestigde landhoeve. 


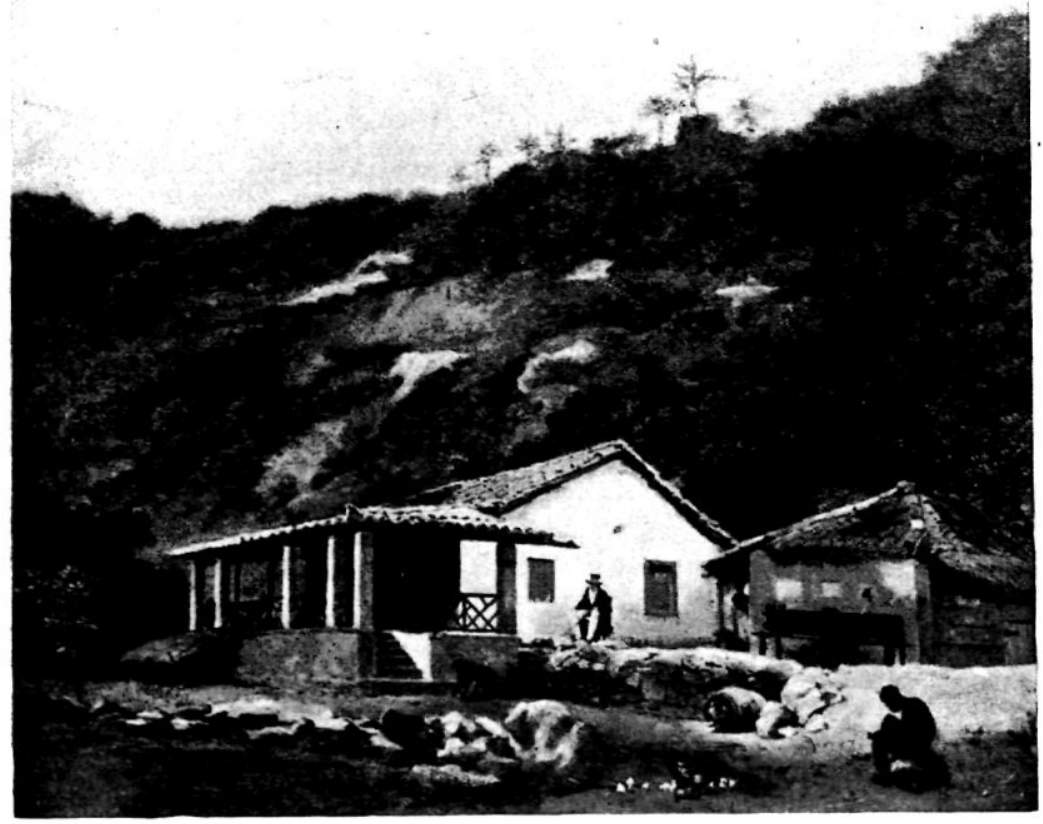

De landhoeve van Dirk van Hogendorp nabij Rio de Janeiro, in ongeveer 1820 , naar een schilderij uit dien tijd.

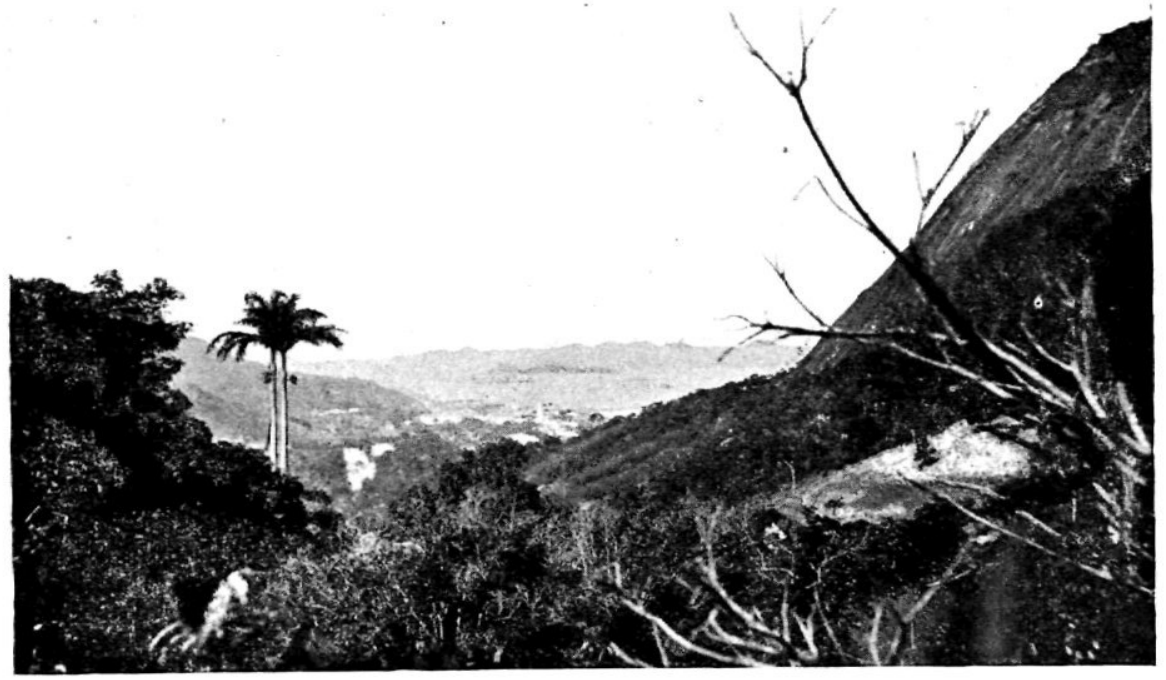

Gezicht op Rio de Janeiro, gephotographeerd in 1922 op de plaats, waar de landhoeve van Dirk van Hogendorp heeft gestaan. 
zijn nog over en bewijzen hunnen ouderdom door de voor de behuizing, ten minste een eeuw geleden, geplante koningspalmen.

Van Hogendorp had hier zijn Braziliaansche landhoeve gehuurd van den Engelschman William Young, die zelf haar had overgenomen van den Britschen Consul-Generaal te Rio, Henry Chamberlain (Sillem, blz. 313-314, 344).

3. Het terrein, door Sillem beschreven, geleek sterk op dat, waar zich heden ten dage bevindt een voormalige koffiefazenda, in den volksmond Pao da Bandeira geheeten naar een vlaggemast die er gestaan heeft, gelegen aan een bocht van den straatweg (vroeger muildierpad), die van Silvestre, een huizencomplex op de helling van den Corcovado, naar de Rua Cosme Velho en Laranjeiras leidt. Deze vroegere fazenda bevat thans drie oude huizen; achter het oudste, in de rots uitgehouwen, een kelder. Men vindt er sporen van een regelmatigen koffie-aanplant en oude oranjeboomen. Het terras, waarop de fazenda ligt, draagt een rij zeer oude koningspalmen.

4. Door bemiddeling van den Britschen ambassadeur werd de hand gelegd op het bij Sillem (blz. 320) genoemde boek van Mrs. Maria Graham, getiteld "Journal of a Voyage to Brazil», London, $1824^{1}$, waarin niet alleen haar twee bezoeken op NovoSion vermeld staan, doch waarin ook gereproduceerd is een teekening van haar hand van het uitzicht, dat men van NovoSion op Rio had. Had het Mr. Pleyte bij een wandeling langs de fazenda Pao da Bandeira reeds getroffen, hoeveel punten van overeenkomst (o.a. een oud, steil muildierpad, dat naar beneden voert) deze weg vertoonde met de beschrijving bij Sillem, bij een nadere omzwerving in deze buurt ontdekte hij in de wildernis langs den straatweg eenige terrassen, en vond aldaar, gewapend met Maria Graham's teekening en na photografische opneming van ettelijke daarmede gelijkenis vertoonende uitzichten, de plek, waar zij had zitten schetsen. Aan den voet van de helling, waar Novo-Sion vermoed werd, ligt een aan de gemeente Rio behoorende hofstede, met stallen, bijgebouwen en bloementuin, naar het uiterlijk te oordeelen van jongere dagteekening dan Van Hogendorp's chacara en niet strookend met Sillem's beschrijving.

5. Men beschikt te Rio niet over registers, waarin de namen

1 Van dit werk bevindt zich een Spaansche vertaling in de Koninklijke Bibliotheek te 's-Gravenhage. 
der rechthebbenden op onroerende goederen worden opgenomen, maar het is niet uitgesloten van een bepaald aangeduid terrein de namen der rechthebbenden op te sporen.

Maria Graham's schets is gemaakt of een heuvel "Morro do Inglez», de Heuvel van den Engelschman geheeten. Uit de archieven te Rio kon met notariëele stukken worden aangetoond, die aan Mr. Pleyte ter inzage werden gegeven, dat "uma chacara, com casa de vivenda, fructeiras e bemfeitorias, een landhoeve met een woonhuis, vruchtboomen en wat daar verder toe behoort, eigendom van Pater Antonio Benedicto de Souza op 28 November 1816, verkocht was aan Henry Chamberlain. Deze Henry (Hen. rique) Chamberlain (Sillem, blz. 313-314, 344) heeft de chacara op 17 September 1819 blijkens notariëele acte verkocht aan William (Guilherme) Young.

Van Hogendorp kwam op 10 Februari 1817 te Rio aan (Sillem, blz. 313) en onderhandelde eerst over den aankoop, later over de huur van het goed, in het voorjaar van 1817 (Sillem, blz. 313) vermoedelijk met Chamberlain en later met Young (Sillem, blz. 313), die vóórdat hij eigenaar van de chacara werd haar al in gebruik had.

De grensomschrijving van de chacara zooals zij wordt gegeven in de notariëele acten van 1817 en 1819 is geheel van toepassing op het terrein, dat thans in den volksmond nog "Morro do Inglez " heet.

Waar archiefstukken, teekening en grensomschrijving aldus overeenstemden, scheen de gezochte plek te zijn gevonden.

De oude "hofstede», die er thans staat, behoort met stallingen, bijgebouwen en bloementuin aan den dienst van «'s lands waterleidingen» van de Vereenigde Staten van Brazilië. De ingang tot het landgoed in zijn tegenwoordigen vorm wordt geflankeerd door twee zeer hooge, zeker wel een eeuw oude, koningspalmen; het huis is met de voorgalerij derwaarts gekeerd. Op een voorpleintje zijn bloem- en grasperken; onder een manggaboom is de voor dat doel vervaardigde gedenksteen voor Dirk van Hogendorp opgericht, met zijn opschrift gekeerd naar den straatweg. Van Hogendorp's huis stond misschien iets meer naar den woudzoom toe, doch daar bevinden zich werkplaatsen van den genoemden tak van staatsdienst, die voor opstelling van den steen geen gelegenheid boden. De Ladeira das Escuras, het steile, nu bestrate muildierpad, waar Dirk een val van zijn 
DE WONING VAN DIRK VAN HOGENDORP IN BRAZILIË 645 paard deed, zoodat Dom Pedro hem kwam bezoeken (Sillem, blz. 340) loopt langs het erf.

De Braziliaansche Bondsregeering heeft met groote voorkomendheid het eigendom van den op haar grond geplaatsten steen aanvaard, er een groot bloemperk omheen aangelegd, en de zorg voor onderhoud en omgeving op zich genomen. De Nederlandsche gezant zette op 18 Augustus 1923 in het Instituto Historico e Geographico in een Fransche conférence de beteekenis uiteen van Dirk van Hogendorp als koloniaal hervormer, als generaal van Napoleon en als raadsman van Dom Pedro. 
